\title{
New Telemedicine Guidelines of India: Q and A
}

Rudrajit Paul

Bengal Physician Journal (2019): 10.5005/jp-journals-10070-6124

The new telemedicine guidelines of India have been published on March 25, 2020. We are sure that everyone has gone through it or at least has skimmed through it. Thus, this section is not about describing the guidelines. Instead, it will discuss certain queries about this new guideline, which will be of help to the internists.

\section{Q1. Is a Doctor Bound to Cater to Patients via Telemedicine?}

Ans. No, the use of telemedicine is at the discretion of the doctor. A doctor may refuse it if he/she is not comfortable with it. For example, a doctor may find the use of video chat applications, such as Facetime, difficult. He/she can then refuse to attend patients via that platform. The patient cannot force the doctor to use telemedicine. Also, if the doctor thinks that he/she needs to see the patient physically for optimum management, it is his/ her professional judgment and then he/she is allowed to insist on physical visit.

There is however one exception. If a doctor working in a government setup is asked by the government to do a telemedicine session as a part of epidemic act or Essential Services Maintenance Act (ESMA), then the doctor should not refuse. He/she can however put it on record that he/she has limitations in the use of technology.

\section{Q2. Can a Doctor Charge Fees for Telemedicine Services?}

Ans. Yes, a doctor can and should charge for the service (Section 3.7.3). The consultation will require time and effort on the part of the doctor. Also, the consultation will be subject to laws of the country, including consumer laws. Hence, the doctor cannot do it for free. However, to avoid misunderstanding, it is better to display the charges at the beginning of the session. If the use of a telemedicine platform or Internet incurs an extra charge, then it also has to be paid by the patient, following the rules of the market economy.

\section{Q3. If a Patient Refuses to Give IDENTIFICATION Documents, SHOULD the Telemedicine Session be Done?}

Ans. Ideally, No. The guideline explicitly mentions that telemedicine sessions cannot be anonymous.

\section{Q4. If the Patient is a Minor, can Telemedicine Session be Allowed?}

Ans. Yes, but an adult needs to be present. Also, the adult must be present in the same frame as the minor during the video call and not elsewhere in the room. The identity of the adult needs to be verified also.
Department of Critical Care Medicine, Institute of Postgraduate Medical Education and Research and Seth Sukhlal Karnani Memorial Hospital, Kolkata, West Bengal, India

Corresponding Author: Rudrajit Paul, Department of Critical Care Medicine, Institute of Postgraduate Medical Education and Research and Seth Sukhlal Karnani Memorial Hospital, Kolkata, West Bengal, India, Phone: +91 9433824341, e-mail: r.paul.medicalcollege@gmail. com

How to cite this article: Rudrajit Paul. New Telemedicine Guidelines of India: Q and A. Bengal Physician Journal 2019;6(3):76-78.

Source of support: Nil

Conflict of interest: None

\section{Q5. If the Patient Dies after a Telemedicine Consultation Session, Who will Give the Death Certificate?}

Ans. If the doctor is far away, obviously he cannot provide the death certificate. For writing death certificate, the doctor has to examine the patient physically at the time of writing the certificate. In such cases, the patient's relatives have to arrange for another physician. However, the prescription given during the telemedicine session is a valid proof of the illness to determine the cause of death. But for this to be a valid document, it must have the signature/e-signature of the doctor. Merely a message given over WhatsApp or SMS sent with the name of medicine is not a valid prescription. A doctor should refrain from sending such messages. It is bad practice and not valid as a medicolegal document.

\section{Q6. If a Patient Sends a Photo via WhatsApp which is not Clear, What SHOULD BE Done?}

Ans. The doctor should ask for a clearer photo or ask the patient to send a scanned copy via e-mail. Unless the doctor is sure of the contents of the image, he/she should not give any opinion. If the patient does not have a scanner, then it cannot be helped; the consultation will be paused.

\section{Q7. If the Online Platform for Telemedicine is Hacked, Will the Doctor be Responsible for Data Breach?}

Ans. Hacking can occur at any time. The doctor will NOT be responsible, provided he/she has taken reasonable care for data protection (e.g., not sharing password with outsiders).

(0) The Author(s). 2019 Open Access This article is distributed under the terms of the Creative Commons Attribution 4.0 International License (https://creativecommons. org/licenses/by-nc/4.0/), which permits unrestricted use, distribution, and non-commercial reproduction in any medium, provided you give appropriate credit to the original author(s) and the source, provide a link to the Creative Commons license, and indicate if changes were made. The Creative Commons Public Domain Dedication waiver (http://creativecommons.org/publicdomain/zero/1.0/) applies to the data made available in this article, unless otherwise stated. 


\section{Q8. Can a Doctor Advertise for Telemedicine Consult?}

Ans. No, doctors are not allowed to advertise.

\section{Q9. Can a Doctor Attend a Patient in a Different City via a Video Call?}

Ans. Yes. This is allowed in this new law (Section 1.3.1). But if the doctor and the patient were in different cities at the time of the consultation and later, a consumer case arises, it will be difficult to determine which court will have the jurisdiction. The situation will be even more complex if the doctor and patient are in different countries. For example, at the time of the consult, if the patient was in USA and he/she complains about the doctor in a US court, the Indian doctor will be in a soup. So, it is better not to attend anyone outside the country via online services. Thus, at the beginning of the consultation, the location of the patient should be asked and recorded. Or, some lawyers advice that, when a patient registers for a telemedicine session, it may be informed that all disputes will be subject to jurisdiction of a particular place (which will be convenient for the doctor). This is a common practice in many consumer products.

\section{Q10. If a Patient Calls a Doctor over Phone and Asks for Advice, can that be Considered as a Telemedicine Session?}

Ans. For a telemedicine session to commence, as per this guideline, the doctor should first confirm the identity of the patient (Section 3.2.2). Then the issue of patient consent is to be resolved. A phone call is not enough for these purposes. Also it is very dicey to confirm identity of either the doctor or the patient in a phone call (Section 3.2.1). So it is difficult to consider a mere phone call as a full telemedicine session. Doctors should stop prescribing medicines over phone. A brand name uttered over phone may be misheard and then the patient will take the wrong medicine. A phone call can be used for resolving minor doubts such as confirming the timing of a medicine. But it can never be a full telemedicine session. Outside India, the question of prescribing over phone does not even exist. The National Health Service (NHS, UK) has out-of-hours care service but it is mostly a signposting service where the patients are advised whether to stay at home or go to the emergency room or whether a doctor will make a home visit. Prescribing over phone is not done, except perhaps paracetamol or Gaviscon (which are available over-the-counter in the UK).

\section{Q11. What if the Doctor does not Recall the Previous Visit of the Patient?}

Ans. A doctor may not recall the details of a patient seen earlier. It is the duty of the patient to provide previous medical records. If this is done from a hospital, then the hospital may have the previous records. If nothing is available, then the doctor can consider this as the first visit and proceed as such (Section 3.6.2).

\section{Q12. What Precautions should a Doctor Take to Protect the Patient Data?}

Ans. Breach of personal data is taken very seriously by law. So when a patient entrusts a doctor with his/her personal information, the doctor has to take reasonable care to protect it. Since telemedicine consult takes place over a device like phone or tablet, the device should be protected. It should preferably have a password and others should not be allowed access to it. If the doctor is conducting telemedicine session in a hospital computer, he/she should remember to log out after the end of the session. The telemedicine session should not be conducted from a public computer or in a public place. Images or documents sent by patients should not be stored in public folders or insecure servers. When a doctor first registers with a telemedicine service provider, he/she should enquire about data protection capabilities. According to Section 3.7.1.3, the doctor will not be responsible for data breach if that breach is due to some technical issues beyond his/her control. As a safeguard, a doctor can send an e-mail to the service provider enquiring about the data protection policies. The reply to this mail will be the proof that the doctor has taken adequate care. This mail may be produced in court if a case of data breach arises.

\section{Q13. A Patient Sends a Report via E-mail and Asks for Advice. Is this a Telemedicine Session?}

Ans. Yes, this may be considered as a telemedicine session, provided the patient's identity is confirmed. The doctor can reply via e-mail but the e-mail should have the digital signature and registration number.

\section{Q14. What are the Drugs that can be Prescribed in a Telemedicine Session?}

Ans. The list of drugs is given in the guideline. Everyone should go through it. There will be changes from time to time. For example, after publication of the guideline on March 25, 2020, there was an addition to it on April 11, 2020 to include psychiatric drugs also (MCl-211(2)/2019/Ethics/201874). So these changes have to be remembered. In general, sedatives and opiates are usually not allowed (but again, clonazepam is allowed if it is given for a psychiatric indication).

\section{Q15. Can a Doctor Give a Medical Certificate in a Telemedicine Session?}

Ans. The recent guideline does not mention anything about medical certificate. So it is difficult to comment. But ideally, for a medical certificate, the signature of the patient is required. This cannot be done via a video call.

\section{Q16. If a Minor Requests a Telemedicine Session for a Disease Like Sexually Transmitted Disease or UnWanted Pregnancy, and He/She does not Want an Adult to be Present, can the Doctor Allow This?}

Ans. As per law, this cannot be allowed. Adults must be present with minors. But this is a real-life problem and the doctor may consult with lawyer to find a way out. In the UK, 16 years is taken as the age of consent and anyone above that age need not be accompanied by a guardian. 


\section{Q17. Can All Doctors do Telemedicine Sessions?}

Ans. There is a plan to train all doctors for telemedicine via e-learning over a period of 3 years. Till that time, anyone can do these sessions. But after that, the certification will be needed.

\section{Q18. If a Doctor Treats a Patient via Telemedicine and Subsequently there is a Consumer Case, will His Professional IndEMNITY InSURANCE COVER That?}

Ans. This is difficult to say as of now. The guidelines have just come out. The insurance companies have not come out with any statement. So doctors will have to negotiate with their insurance providers. But before embarking on the telemedicine session, it would be prudent to make the issue clear.

Also, the patients should make clear whether their insurers will cover the treatment.

\section{Q19. Can Telemedicine be Used for EMERGENCIES?}

Ans. Ideally telemedicine should not be used for emergencies as it is remote and we cannot check the patient physically. But if a telemedicine session develops into an emergency, instead of terminating the session, it may be good to signpost the patient to the appropriate medical care.

\section{Q20. If a Patient Sends an E-mail for Advice and the Doctor is Late in Checking His Mall, can This be Taken as Negligence?}

Ans. No, the doctor can check the e-mail at his/her convenience. Under asynchronous modes of communication, there is no fixed time for the doctor's response. Fixed time will be given only for real-time calls like video calls.

\section{Q21. Can a Doctor Record a Telemedicine Session for Future Reference?}

Ans. Yes, provided patient's consent is taken. This consent may be taken at the time of initiation of the session.

\section{Q22. Can a Doctor Consult Another One via Telemedicine Platform?}

Ans. Yes, this is similar to referring your case to another consultant or colleague. The referred doctor can also charge his consultation fees, as he would do for a hospital referral.

\section{Q23. Can a Caregiver such as a Family Member Do a Telemedicine Session on Behalf of the Patient?}

Ans. According to Section 4.2.2, this can be done if the caregiver has the authorization of the patient or if the patient had said so during a previous visit/session.

\section{Q24. What are Some of the Safeguards during a Telemedicine Consultation?}

Ans. Some safeguards can be as follows:

- Do not give lengthy prescriptions. It is better to give medicines for short duration and ask for review.

- Do not accept reports that the patient reads out over phone. Always insist on seeing the reports yourself.

- It is better not to send photos of prescriptions. Either send e-prescriptions via specialized software or send scanned copies. Photos may have omitted portions or distorted sections.

- Do not force patients for a telemedicine session. It is better for the patient to take the initiative.

- If you think the telemedicine session is not going satisfactorily, you can terminate it at any time.

- If the patient uses a new e-mail ID or Whatsapp number which the doctor does not recognize, the doctor can ask the patient to use the previous familiar number.

- Avoid using artificial intelligence for prescription.

- Switch the mode of communication (e.g., from e-mail to video call) during a session if needed.

- The records of the session, e.g., e-mail or Whatsapp messages should be stored and not deleted, at least for some time.

\section{Acknowledgment}

We would like to thank and acknowledge the kind support of Dr Mansij Biswas in preparation of this guideline.

\section{Some Footnotes By the Author}

Telemedicine will be the way forward. So all clinicians should try to familiarize themselves with this technology. In the USA, many famous medical centers such as Mount Sinai and Cleveland Clinic have already started this. Not only is outpatient department consultation via telemedicine becoming familiar but also the electronic intensive care unit is becoming a popular concept.

Telemedicine will not solve all problems, but it may be a good way to continue nonessential medical care in times of a pandemic situation like this. It is better not to use your personal phone number for telemedicine but use a nonpersonal user ID (e.g., for Skype). 